\title{
Efficiency Predictive Factors for Professional Ability of Ramkhamhaeng University Lecturers for ASEAN Socio-Cultural Community
}

\author{
Chomsupak Cruthaka ${ }^{\star}$ \\ Duangduen Chancharoen ${ }^{2}$ \\ Taviga Tungprapa ${ }^{3}$ \\ Apinya Ingard ${ }^{4}$ \\ Pornkul Suksod ${ }^{5}$
}

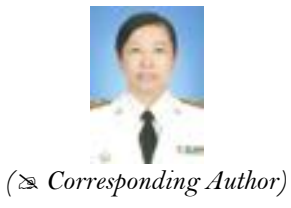

${ }^{12}$ Ramkhamhaeng University, Bangkok, Thailand. Email:cchomsupak@yahoo.com

Srinakharinwirot University, Bangkok, Thailand.

'Silpakorn University, Bangkok, Thailand.

${ }^{5}$ Suan Sunandha Rajabhat University, Bangkok, Thailand.

\begin{abstract}
This study aims to investigate the relationship between the use of information technology for retrieval and communication ability; intercultural learning ability; English ability and interpersonal ability with professional ability of Ramkhamhaeng University (RU) lecturers for ASEAN socio-cultural community (ASCC); and study the efficiency predictive factors of professional ability of RU lecturers for ASCC. The sample population consisting of $295 \mathrm{RU}$ lecturers. The instrument of research was a five-rating scale questionnaire eliciting data concerning the predictive factors of professional ability of RU lecturers for ASCC. The questionnaires were tested for content validity index and the reliability by Cronbach's alpha coefficient were $.91, .95, .85,95$ and .96 respectively. Data were analyzed by frequency, percentage, mean, standard deviation, Person product moment correlation and stepwise multiple regression analysis. Findings: 1. Interpersonal ability; English ability; intercultural learning ability; and the use of information technology for retrieval and communication ability were a positive moderate correlation and the professional ability with statistical significance at the level of .01. $(\mathrm{r}=338, .415, .449$ and .444$)$ 2. The use of information technology for retrieval and communication ability $\left(\mathrm{X}_{1}\right)$; intercultural learning ability $\left(\mathrm{X}_{2}\right)$ and English ability $\left(\mathrm{X}_{3}\right)$ were to predicted professional ability of RU lecturers for ASCC account to 52.70 percent (Adjusted $\mathrm{R}^{2}=.527$ ). The predicted in row score equation as follows: $\mathrm{Y}^{\prime}=1.068+.332\left(\mathrm{X}_{1}\right)+.244\left(\mathrm{X}_{2}\right)+.194\left(\mathrm{X}_{3}\right)$ The predicted in standardized equation as follows: $\mathrm{Zy}^{\prime}=.359\left(\mathrm{Zx}_{1}\right)+.279\left(\mathrm{Zx}_{2}\right)+.244\left(\mathrm{Zx}_{3}\right)$.
\end{abstract}

Keywords: Predictive factors, Professional standards, Ramkhamhaeng university lecturers, ASEAN socio-cultural community.

Citation | Chomsupak Cruthaka; Duangduen Chancharoen; Taviga Tungprapa; Apinya Ingard; Pornkul Suksod (2020). Efficiency Predictive Factors for Professional Ability of Ramkhamhaeng University Lecturers for ASEAN Socio-Cultural Community. Asian Journal of Education and Training, 6(3): 536-540.

History:

Received: 5 June 2020

Revised: 8 July 2020

Accepted: 12 August 2020

Published: 1 September 2020

Licensed: This work is licensed under a Creative Commons

Attribution 3.0 License (cc) Er

Publisher: Asian Online Journal Publishing Group
Acknowledgement: All authors contributed to the conception and design of the study.

Funding: This study received no specific financial support

Competing Interests: The authors declare that they have no conflict of interests.

Transparency: The authors confirm that the manuscript is an honest, accurate, and transparent account of the study was reported; that no vital features of the study have been omitted; and that any discrepancies from the features of the study have been omitting
study as planned have been explained.

study as planned have been explained.
Ethical: This study follows all ethical practices during writing.

\section{Contents}

1. Introduction

2. Research Objectives

3. Research Methodology

4. Results

5. Discussion

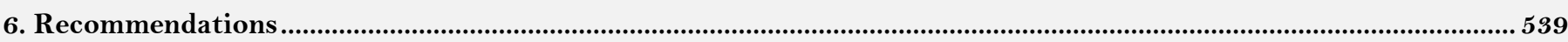

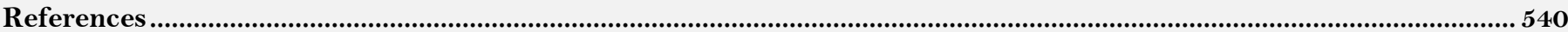




\section{Contribution of this paper to the literature}

This study contributes to the existing literature by investigating the relationship between the use of information technology for retrieval and communication ability; intercultural learning ability; English ability and interpersonal ability with professional ability of Ramkhamhaeng University (RU) lecturers for ASEAN socio-cultural community (ASCC); and study the efficiency predictive factors of professional ability of RU lecturers for ASCC.

\section{Introduction}

The core of future is to create mutual identity across ASEAN member countries, or ASEAN identity. Due to the need for joint development and the existence of diversity in terms of geographical areas, languages, ethnic groups, and ecological surroundings, this notion will support the diverse nature of ASEAN identity while promoting the sense of caring and sharing (Srisoothikerdporn, 2012).

Hence, all universities should cooperate in building this mutual identity. This is because the emergence of ASEAN Economic Community (AEC) will stimulate the mobility of scholars and professionals of other fields across member countries, so as to establish a research and development institute to serve as an excellent center, out of which products and innovations will arise from constructive development from ASEAN member countries. However, even in this globalized era, the education system in Thailand is still offering a teacher-oriented learning format, hence restricting the students' knowledge acquisition. This incident stems basically from the teacher's limited capability as an individual to pursue and process the availability of overabundant information, as well as the student's own ability to search for information by him/herself. Hence, the inability to retrieve existing information and filter out incoming information, together with the inability to build and apply the acquired knowledge, will eventually hinder the instructional processes and outcomes to keep track with rapidly-changing technologies (Bureau of International Cooperation Strategy the Office of the Higher Education Commission, 2010).

At present, the instruction process has been shifted to be learner-oriented, in which the course syllabus clearly displayed the notion of knowledge self-acquisition. In other words, in-class content provision has been reduced due to the availability of contents in online systems, but to be replaced by the focus on cultivating the systematic thinking, together with critical and analytical thinking, so as to implant the students with creativity, courage to experiment unconventional practices, and willingness to listen to others. Moreover, the current educational process also includes the evaluation of other elements beyond subject-specific contents. The content itself is posted on e-learning website to facilitate easy access among the learners. The classroom will focus primarily on the knowledge acquisition process via discussion, arguments, critiques, analytical evaluation, and synthesis of related concepts. These activities are expected to light up challenging issues and get Thailand prepared for stepping in the society of creative economy (Wattanasirichaikool, 2009).

RU is administered in a 'knowledge market' type, in which instructional advancement has been marked up as its core value. To keep track with fast changes in the globalized era, the university has been offering a number of modern programs of both in-class and distance systems to both local and international students at the bachelor's, the master's, and the doctoral levels, with new programs constantly offered. All programs have also been standardized and verifiable under the quality assurance management (Ramkhamhaeng University, 2020).

Therefore, with regard to ASEAN socio-cultural community, as well as the diversity of races, religions, and traditions across ASEAN member countries, the lecturers of RU are required to conduct self-development to achieve professional standards, acquire proficiency in English language, adept in ASEAN culture, and be able to use information technology as well as develop interpersonal ability (Cruthaka, 2011).

\section{Research Objectives}

The purpose of this research was to study of relationship between the use of information technology for retrieval and communication; intercultural learning; English ability and interpersonal ability with professional ability of RU lecturers for ASCC. And study the efficiency predictive factors of professional ability of RU for ASCC.

\section{Research Methodology}

The researcher conducted a survey of opinions regarding factors of professional ability of RU for ASCC under study. Using the method of proportional stratified random sampling as applied to the ten faculties at which the lecturers were employed, the researcher thereby constituted a sample population consisting of 295 RU lecturers. The information on personal characteristics of RU lecturers consisted of 178 men (60.30\%) and 117 women (39.70\%). 72 lecturers $(24.40 \%)$ are in the age group of $25-35,83$ lecturers $(28.14 \%)$ are in the age group of $36-45$, 60 lecturers $(20.34 \%)$ are in the age group of $46-55$, and 80 lecturers $(27.12 \%)$ are in the age group of 56 years old or over. 204 lecturers $(69.20 \%)$ have education master degree and 91 lecturers $(30.80 \%)$ have education doctor degree.

The instrument of research was a five-rating scale questionnaire eliciting data concerning factors of professional ability of RU lecturers for ASCC. The first part of the questionnaire was brought out as information about the demographic characteristics of the respondents using checklists. In the second part of the questionnaire, the researcher uses the data obtained from the questionnaire about interpersonal ability; English ability; intercultural learning ability; the use of information technology for retrieval and communication and professional ability of RU lecturers for ASCC. Testing for quality, the researchers found that the instruments evinced reliability at the levels of $.91 ., .95, .85, .95$, and .96 respectively. Using techniques of descriptive statistics, the researchers analyzed the data collected in terms of frequency, percentage, mean and standard deviation. In addition, Person product moment correlation and stepwise multiple regression analysis.

\section{Results}

The results of the study of the predictive factors for professional ability of RU lecturers for ASCC as following: 
Table-1. Means and standard deviation and the level of opinions to the predict factors of professional ability of RU lecturers for ASCC

\begin{tabular}{l|c|c|c}
\hline Variable & $\bar{X}$ & SD & Opinions level \\
\hline Interpersonal ability & 3.79 & .65 & high \\
\hline English ability & 3.90 & .67 & high \\
\hline Intercultural learning ability & 3.81 & .61 & high \\
\hline $\begin{array}{l}\text { The use of information technology for retrieval and communication } \\
\text { ability }\end{array}$ & 4.11 & .57 & high \\
\hline Professional ability & 4.12 & .53 & high \\
\hline Total & 3.95 & .49 & high \\
\hline
\end{tabular}

Table 1 show that these RU lecturers exhibited levels of opinions regarding the predictive factors of professional ability of RU lecturers for ASCC in an overall picture and in all aspects at a high level.

Table-2. Relationship Between interpersonal ability; English ability; intercultural learning ability; the use of information technology for retrieval and communication ability with professional ability of RU lecturers for ASCC.

\begin{tabular}{l|c|c}
\hline Variable & \multicolumn{2}{c}{ Professional ability } \\
\cline { 2 - 3 } & $\mathbf{R}$ & p-value \\
\hline Interpersonal ability & $.338^{* *}$ & .000 \\
\hline English ability & $.415^{* *}$ & .000 \\
\hline Intercultural learning ability & $.449^{* *}$ & .000 \\
\hline $\begin{array}{l}\text { The use of information technology for retrieval and communication } \\
\text { ability }\end{array}$ & $.444^{* *}$ & .000 \\
\hline
\end{tabular}

Table 2 show that interpersonal ability; English ability; intercultural learning ability; and the use of information technology for retrieval and communication ability were a positively and moderately correlation to the professional ability at the 0.01 significant level $(\mathrm{r}=338, .415, .449$ and .444$)$. While the aspect relation to intercultural learning ability had a highest, the next were the use of information technology for retrieval and communication ability; English ability; and interpersonal ability respectively.

Table-3. Regression coefficients of independent variables in the RU lecturers' professional ability for ASCC model.

\begin{tabular}{l|c|c|c|c|c}
\hline Independent Variable & B & SEB & Beta & t & p-value \\
\hline $\begin{array}{l}\text { The use of information technology for retrieval and } \\
\text { communication ability }\left(\mathrm{X}_{1}\right)\end{array}$ & & & & & \\
\hline Intercultural learning ability $\left(\mathrm{X}_{2}\right)$ & .332 & .048 & .359 & 6.897 & .000 \\
\hline English ability $\left(\mathrm{X}_{3}\right)$ & .194 & .045 & .279 & 5.398 & .000 \\
\hline Constant & 1.068 & .170 & & 6.298 & .000 \\
\hline $\mathrm{R}=.729 \quad \mathrm{R}^{2}=.532 \quad$ Adjusted $\mathrm{R}^{2}=.527 \quad \mathrm{SE}_{\mathrm{est}}=.36478$ & $\mathrm{~F}=110.327 \quad \mathrm{p}$-value=.000 \\
\hline Note: $* \mathrm{p}<.05$
\end{tabular}

Table 3 show that Constant $=1.068$, regression coefficient $(\mathrm{B})$ for predictive professional ability $(\mathrm{Y})$ of the use of information technology for retrieval and communication ability $\left(\mathrm{X}_{1}\right)=.332$; intercultural learning ability $\left(\mathrm{X}_{2}\right)=$ .244; and English ability $\left(\mathrm{X}_{3}\right)=.194$. (Show that equation 1)

A part of regression standardized coefficient (Beta) for predictive professional ability $\left(Z_{\mathrm{y}}\right)$ of the use of information technology for retrieval and communication ability $\left(\mathrm{Zx}_{1}\right)=.359$; intercultural learning ability $\left(\mathrm{Zx}_{2}\right)=.279$; and English $\operatorname{ability}\left(\mathrm{Zx}_{3}\right)=.244$. . (Show that equation 2$)$.

The aspect regression coefficient of the use of information technology for retrieval and communication ability $\left(\mathrm{X}_{1}\right)$ had a highest in predictive professional ability (Y) of RU lecturers for ASCC, the next were intercultural learning ability $\left(\mathrm{X}_{2}\right)$, and English ability $\left(\mathrm{X}_{3}\right)$ respectively. ASCC.

The result of regression analysis for constructed prediction equation of professional ability of RU lecturers for

The predicted in row score equation as follows:

$$
\mathrm{Y}^{\prime}=1.068+.332\left(\mathrm{X}_{1}\right)+.244\left(\mathrm{X}_{2}\right)+.194\left(\mathrm{X}_{3}\right) \quad 1
$$

The predicted in standardized equation as follows:

$$
\mathrm{Zy}^{\prime}=.359\left(\mathrm{Zx}_{1}\right)+.279\left(\mathrm{Zx}_{2}\right)+.244\left(\mathrm{Zx}_{3}\right)
$$

The efficiency of predictive equation:

The use of information technology for retrieval and communication ability $\left(\mathrm{X}_{1}\right)$, intercultural learning ability $\left(\mathrm{X}_{2}\right)$, English ability $\left(\mathrm{X}_{3}\right)$ predicted professional ability of RU for ASCC to account for 52.70 percent (Adjusted $\left.\mathrm{R}^{2}=.527\right)$.

\section{Discussion}

The discussion to answer the two research objectives are as follows:

1. Interpersonal ability; English ability; intercultural learning ability; and the use of information technology for retrieval and communication ability were a positively and moderately correlation to the professional ability at the 0.01 significant level. The related discussions are as following:

1.1 Interpersonal ability was found to correlate positively in a moderate level with professional ability at the 0.01 significant level $(\mathrm{r}=.338$ (. This finding may stem from the fact that the lecturers usually use interpersonal ability, be it writing, speaking, and expressing non-verbal postures, to convey meanings of transmitted information to individuals who engaged in interactions in instructional process management in ASCC, hence yielding a positive relationship with professional ability among the university lecturers. The said findings also coincided with Selvi (2010) study that an individual's social and cultural ability, emotional ability, and communication ability not only exerted an influence on values, behaviors, communication, and performance goals in school, but also supported professional development. 
1.2 English ability was found to correlate positively in a moderate level with professional ability at the 0.01 significant level $(r=.415$ (. This finding may stem from the fact that English is a necessary tool for RU lecturers to be used in retrieving information and examining research concepts relating to instructional improvement and exchanges of academic knowledge and professional experiences. The finding agreed with Youxing (2010) study on evaluation of a shortterm exchange program of language and culture between Dali University, Shina University, and Burapha University, in which life experiences, learning experiences, English communication, culture, and participation in the program, jointly functioned to develop understanding about internalization. The research findings also stated that Chinese students possessed expertise with regards to the use of English in communication.

The above finding also coincided with Kamaruddin and Ibrahim (2010) research on improving competency of teaching methods of Malaysian lecturers using a career-development program. They concluded that the Malaysian lecturers need to improve their English ability in listening, speaking, and writing skills.

1.3 Intercultural learning ability was found to correlate positively in a moderate level with professional ability at the 0.01 significant level $(r=.449$. This may stem basically from the necessity of RU lecturers to be equipped with knowledge relating to cultural and traditions to be applied in their international-oriented teaching and professional development in the ASEAN context. The aforesaid findings are also in congruence with Toatong (2011) paper on the integration of cross-cultural learning through the tourism academic program in AEC, focusing particularly on Thailand's case. The study reported that the said integration could be achieved through mutual cooperation among related academic institutes with regards to holding exchange programs of culture, and lecturers \& students, and joint research or co-production of textbooks across universities. The study of Selvi (2010) also supported this notion by stating that social and cultural ability exerted an influence on values, behaviors, communication, and performance goals in school.

1.4The ability to use information technology for retrieval and communication was found to correlate positively in a moderate level with professional ability at the 0.01 significant level $(r=.444$. This may stem basically from the role of technology deemed necessary among RU lecturers in rendering attractive learning via electronic instructional materials, web teaching, and social media. The quality of instructions is expected to be uplifted due to easy access to knowledge without time and place restrictions. The findings also agreed with Cruthaka (2018) who stated that technological competency enables lecturers to achieve knowledge access and retrieval, as well as learning exchanges, knowledge application in instructions and related material development, and all-time learning supports both in the synchronized (interaction between teachers and learners) and asynchronized (self-learning as desired by learners) dimensions. Therefore, the ability to use information technology for retrieval and communication was found to correlate positively with professional ability of RU lecturers.

2. The ability to use information technology for retrieval and communication, intercultural learning ability, and English ability, were found to create a model to predict 52.70 percent of professional ability among RU lecturers in ASCC. The related discussions are as following:

2.1 The ability to use information technology for retrieval and communication could predict professional ability RU lecturers in ASCC. This finding may be explained that the ability to use of information technology for retrieval and communication is a critical factor for RU lecturers to use those technologies in handling instructions via networks, long distance, or via websites, together with the invention of development of e-materials, and retrieval of related research to create academic outputs in ASCC. The findings also coincided with Youxing (2010) who stated that the application of technology as a basis for learning could be done by using Web-based learning, teleconferencing, TV, Internet, Intranet, computer-based training, and virtual reality. In this aspect, the provision of learning-support equipment and learning-constructive environments should be made available through the production of learning-facilitating modules and multimedia, hence reinforcing the lecturers' technological potentials in knowledge gathering and disseminating, as well as knowledge retrieval. The above finding is also in congruence with Cruthaka and Pinngern (2016) study in that the university lecturers are able to handle their instructions via website and network systems, crate multimedia to be used in lecturing and assisted instructions, and use technology in speedy retrieval of research papers.

2.2 Intercultural learning ability could predict professional ability RU lecturers in ASCC. This finding may be explained by the fact that, in ASEAN socio-cultural community, the lecturers need to acquire knowledge about arts \& culture, as well as differences in races, languages, religions and traditions of ASEAN member countries, so that understanding and clear communication could be facilitated. The finding was in congruence with Wichasin (2011) study on the integration of cross-cultural learning through tourism academic programs among the AEC member countries, focusing particularly on Lao PDR and Malaysia. The findings revealed that Lao PDR had well promoted, among its students, knowledge in and understanding of its own culture, thereby creating open-minded attitudes among the students regarding the awareness and respect of different cultures.

2.3 English ability could predict professional ability RU lecturers in ASCC. This finding may be explained by the fact that RU lecturers considered English as an important tool in communication, be it speaking, writing, or database retrieving in ASCC. Moreover, English is normally used as a second language across ASEAN member countries, while being stated in the ASEAN charter as a formal language of ASEAN (The Department of ASEAN Affairs Ministry of Foreign Affairs, 2013). As a result, English ability could account for 4.30 percent of variances in professional ability among RU lecturers.

\section{Recommendations}

1. The university should support faculty development to achieve professional ability at the international standards. This outcome could be attained by using a development plan to improving English ability, together with the ability to use information technology for retrieval and communication, and continual learning of traditions and cultures across countries.

2. The factor relating to information technology for retrieval and communication ability could predict at the highest level the professional ability among Ramkhamhaeng University lecturers in ASEAN socio-cultural community. Therefore, Ramkhamhaeng University should update its database on a regular basis, together with 
forming a learning network with other universities in ASEAN. This action will definitely uplift the faculty members' professional ability to the international standards.

\section{References}

Bureau of International Cooperation Strategy the Office of the Higher Education Commission. (2010). Thailand higher education strategy to readiness towards ASEAN community 2015. Bangkok: Bangkok blog.

Cruthaka, C. (2011). Identification of human resource development need in ASEAN community. The Journal of Faculty of Applied Arts, 4(2), 63-70.

Cruthaka, C. (2018). The technological competencies of university lecturers: Applications to Instructional management in ASEAN socio-cultural community. Paper presented at the ASEAN on the Path of Community Conference Proceeding. December 11, 2018, Ramkhamhaeng University.

Cruthaka, C., \& Pinngern, O. (2016). Development of a training program for enhancement of technology competencies of university lecturers. International Journal of Educational Administration and Policy Studies, 8(6), 57-65.Available at: https://doi.org/10.5897/ijeaps2016.0465.

Kamaruddin, W. N., \& Ibrahim, M. S. (2010). Enhancing Malaysian polytechnic technical lecturers' competency through the identification of professional development programs. Procedia Social and Behavioral Sciences, 7, 446-454.Available at: https://doi:10.1016/j.sbspro.2010.10.061

Ramkhamhaeng University. (2020). Introductiom Ramkhamhaeng University. Retrieved from http://www.oasc.ru.ac.th/. [Accessed October 15, 2007].

Selvi, K. (2010). Teachers' competencies. Cultura International Journal of Philosophy of Culture and Axiology, 7(1), 167-175.

Srisoothikerdporn, P. (2012). ASEAN community 2015. Bangkok: Panyachon Distributor.

The Department of ASEAN Affairs Ministry of Foreign Affairs. (2013). 58 answers to the ASEAN community 2018 (2nd ed.). Bangkok: Ministry of Foreign Affairs.

Toatong, C. (2011). Learning each other through ASEAN tourism education: The case of Thailand. A Research Copyrighted by the Association of Thai Tourism Academic. (Project Code: TRI/ASEAN/0003, support by The Thailand Research Fund).

Wattanasirichaikool, S. (2009). National strategic plan for development of thailand before entering the ASEAN economic community in 2015. A Research Copyrighted by Office of the Election Commission.

Wichasin, P. (2011). Learning each other through ASEAN tourism education: The case of Lao' people democratic republic and federation of Malaysia. A Research Copyrighted by Suan Dusit University. (Project Code: TRI/ASEAN/0006, support by The Thailand Research Fund).

Youxing, X. (2010). Evaluation of the short-term international language and culture exchange program: A qualitative approach. Human Resource Development Journal, 1(1), 69-77. 